Journal of Animal and Veterinary Advances 10 (1): 73-80, 2011

ISSN: $1680-5593$

(C) Medwell Journals, 2011

\title{
Development and Validation of a Gas Chromatography-Mass Spectrometry Method for the Simultaneous Determination of Melamine and Cyromazine in Animal Feeds
}

\author{
Binru Shang, Yiqiang Chen, Zongyi Wang, Wenjun Yang and Liying Zhang \\ State Key Laboratory of Animal Nutrition, College of Animal Science and Technology, \\ China Agricultural University, 100193 Beijing, People's Republic of China
}

\begin{abstract}
A new method for simultaneous determination of melamine and cyromazine in animal feeds using Gas Chromatography-Mass Spectrometry (GC-MS) was developed and validated. Samples were extracted with trichloroacetic acid solution cleaned up by cation exchange solid-phase extraction cartridges and derivatized with $\mathrm{N}$, O-bis (trimethylsilyl) trifluroacetamide containing $1 \%$ trimethylchlorosilane followed by GC separation and MS detection. The limits of quantification were $0.10 \mathrm{mg} \mathrm{kg}^{-1}$ for both melamine and cyromazine. Recoveries from feeds spiked at levels between 0.1 and $50 \mathrm{mg} \mathrm{kg}^{-1}$ ranged from $84.2-99.5 \%$ with Relative Standard Deviation (RSD) $<8 \%$ with the exception of a $10.2 \%$ RSD for $0.1 \mathrm{mg} \mathrm{kg}^{-1}$ melamine. This validated method was successfully applied to commercial feed samples showing that it can be used as a routine tool for the surveillance and evaluation of the presence of melamine and cyromazine in animal feeds.
\end{abstract}

Key words: Melamine, cyromazine, gas chromatography-mass spectrometry, feeds, determination

\section{INTRODUCTION}

Cyromazine (N-cyclopropyl-1, 3, 5-triazine-2, 4, 6triamine) is a triazine-based insect growth regulator used as a feed additive to control flies in livestock facilities and as a foliar spray to control insects such as Leaf miners on ornamental and vegetable crops (Toth and Bardalaye, 1987). It is approved for continuous inclusion in feeds for poultry at the medication dosage of $5 \mathrm{mg} \mathrm{kg}^{-1}$ for 4-6 weeks to improve the barn environment. Although, cyromazine has low toxicity (Arnold, 1990) and was classified only as a Group E carcinogen (evidence of non-carcinogenicity for humans) by the Environmental Protection Agency, it metabolizes via de-alkylation reactions in both plants and animals to form the compound melamine (1, 3, 5-triazine-2, 4, 6-triamine) (Cook et al., 1984; Cabras et al., 1990; Lim et al., 1990).

Melamine is also a triazine-based industrial chemical which is used in the manufacture of plastics, flame retardants and other products (Andersen et al., 2008). However, in recent years it has been added illegally into feedstuffs or foods to artificially distort their crude protein contents. Although, melamine is of low toxicity, it could combine with cyanuric acid to form crystals in the kidney and consequently obstruct and damage renal tubules and thereby cause renal failure (Brown et al., 2007, Puschner et al., 2007). The maximum amount of melamine allowed in animal feed is $2.5 \mathrm{mg} \mathrm{kg}^{-1}$ according to the latest rulings from the United Nations food standards body Codex Alimentarius Commission (FAO, 2010). Thus, in order to differentiate between low levels of unavoidable melamine occurrence and deliberate adulteration as well as the abuse of cyromazine in feeds, it is indispensable to develop a robust method to determine melamine and cyromazine in animal feeds.

The analytical methods for melamine or both melamine and cyanuric acid in animal feeds especially pet foods by Gas Chromatography-Mass Spectrometry (GC-MS) (FDA, 2007) or Liquid Chromatography (LC)-MS-MS (Luan et al., 2007; Vail et al., 2007; Heller and Nochetto, 2008; Sakuma and Schreiber, 2008; Smoker and Krynitsky, 2008; Varelis and Jeskelis, 2008) have been reported. Recently, Xia et al. (2010) reported a method for cyromazine determination in poultry feeds by LC-MS-MS. Regarding simultaneous determination of melamine and cyromazine, most previously published methods are related to their residues in foods of animalorigin such as beef, pork, chicken, tilapia, egg and milk (Chou et al., 2003; Wei et al., 2009; Zhu et al., 2009).

However, there have been no reports so far on the simultaneous determination of melamine and cyromazine in feeds by GC-MS. Actually, the matrix of feeds is more variable which have high concentrations of vitamins, minerals and other additives.

The previous research results have shown that the extraction and clean-up procedures are the key steps of chemicals analysis in feeds (Wang and Zhang, 2006). The aim of this research was to develop and validate a precise,

Corresponding Author: Liying Zhang, State Key Laboratory of Animal Nutrition, College of Animal Science and Technology, China Agricultural University, 100193 Beijing, People's Republic of China 
reliable and sensitive method that could simultaneously detect and confirm melamine and cyromazine in feeds and special attention was paid to sample preparation.

\section{MATERIALS AND METHODS}

Chemicals, reagents and standards: Melamine (purity> 99\%), cyromazine (purity $>99 \%$ ) as well as HPLC grade methanol and acetonitrile were purchased from SigmaAldrich (St. Louis, MO, USA). The derivatization reagent $\mathrm{N}$, O-bis (trimethylsilyl) trifluroacetamide (BSTFA) with $1 \%$ Trimethylchlorosilane (TMCS) was purchased from Supelco (Bellefonte, PA, USA). All other chemicals and solvents used were of analytical grade from Beijing Reagent Corporation (Beijing, China). Purified water was obtained with a Milli-Q Water Purification System (Millipore, Bedford, MA, USA). Solutions used in the procedure included $50 \%(\mathrm{v} / \mathrm{v})$ acetone/methanol, $0.5 \%(\mathrm{v} / \mathrm{v})$ ammonium hydroxide/methanol, $10 \mathrm{~g} \mathrm{~L}^{-1}$ trichloroacetic acid solution and $22 \mathrm{~g} \mathrm{~L}^{-1}$ lead acetate solution.

Individual stock solutions of cyromazine and melamine $\left(100 \mu \mathrm{g} \mathrm{mL}^{-1}\right.$ ) were prepared by dissolving appropriate amounts of analytes in $50 \%(\mathrm{v} / \mathrm{v})$ acetone/methanol and were stored at $-20^{\circ} \mathrm{C}$. Mixed working and fortification solutions were prepared freshly by diluting stock solutions with $50 \%(\mathrm{v} / \mathrm{v})$ acetone/methanol.

GC-MS instrumentation: An Agilent 6890 Plus Gas Chromatograph equipped with a 7683 Series Auto Sampler and an Agilent $5973 \mathrm{~N}$ Mass Selective Detector (Agilent Technologies, Santa Clara, CA, USA) was used for analysis. The gas chromatograph was fitted with a DB-5MS column obtained from Agilent J and W Scientific (Folsom, CA, USA). All injections of $1 \mu \mathrm{L}$ were made in splitless mode and the mass spectrometry system was operated in the selected ion-monitoring mode. Helium was used as the carrier gas at a flow rate of $1 \mathrm{~mL} \mathrm{~min}^{-1}$ with a filament delay of $7 \mathrm{~min}$. The injection block temperature was set at $250^{\circ} \mathrm{C}$ while the mass spectrometry interface was $280^{\circ} \mathrm{C}$. The source and analyzer temperatures were held constant at 230 and $150^{\circ} \mathrm{C}$, respectively. Initial column temperature was $80^{\circ} \mathrm{C}$ and was then increased to $230^{\circ} \mathrm{C}$ at a rate of $20^{\circ} \mathrm{C} \mathrm{min}^{-1}$ and held for $2 \mathrm{~min}$. Afterward it ascended to $300^{\circ} \mathrm{C}$ at a rate of $30^{\circ} \mathrm{C} \mathrm{min}$. The characteristic ions used for confirmation for each analyte shown in Table 1 and Fig. $1 \mathrm{a}$ and $\mathrm{b}$ were acquired

Table 1: Typical retention time, characteristic ions and relative ion intensities used for GC-MS analyses

\begin{tabular}{lcccc}
\hline \multicolumn{5}{c}{ intensities used for GC-MS analyses } \\
Compound & $\begin{array}{c}\text { Characteristic } \\
\text { ion }(\mathrm{m} / \mathrm{z})\end{array}$ & $\begin{array}{c}\text { Ron }(\mathrm{m} / \mathrm{z}) \\
\text { Intive intensity }\end{array}$ & $\begin{array}{c}\text { Typical ratio } \\
\text { (base peak } \%)\end{array}$ & $\begin{array}{c}\text { Acceptance } \\
\text { range }(\%)\end{array}$ \\
\hline Melamine & 99,171, & $99 / 327$ & 21.2 & $18.0-24.4^{\mathrm{c}}$ \\
& $327^{\mathrm{b}}, 342$ & $171 / 327$ & 48.9 & $41.6-56.2^{\mathrm{c}}$ \\
& & $342 / 327$ & 51.7 & $46.5-56.9^{\mathrm{d}}$ \\
Cyromazine & 171,181, & $171 / 295$ & 31.8 & $27.0-36.6^{c}$ \\
& $295^{\mathrm{b}}, 310$ & $181 / 295$ & 37.7 & $32.0-43.4^{\mathrm{c}}$ \\
& & $310 / 295$ & 68.4 & $61.6-75.2^{\mathrm{d}}$ \\
\hline
\end{tabular}

aThe typical ratios were measured for the $6 \mu \mathrm{g} \mathrm{mL} \mathrm{m}^{-1}$ calibrating standard injected. ${ }^{b}$ Base ion. ${ }^{c}$ and ${ }^{d}$ the acceptance ranges of relative intensity were calculated from \pm 15 and $\pm 10 \%$ of the typical ratio according to the commission decision of the European community (Commission Decision $2002 / 657 / \mathrm{EC}$

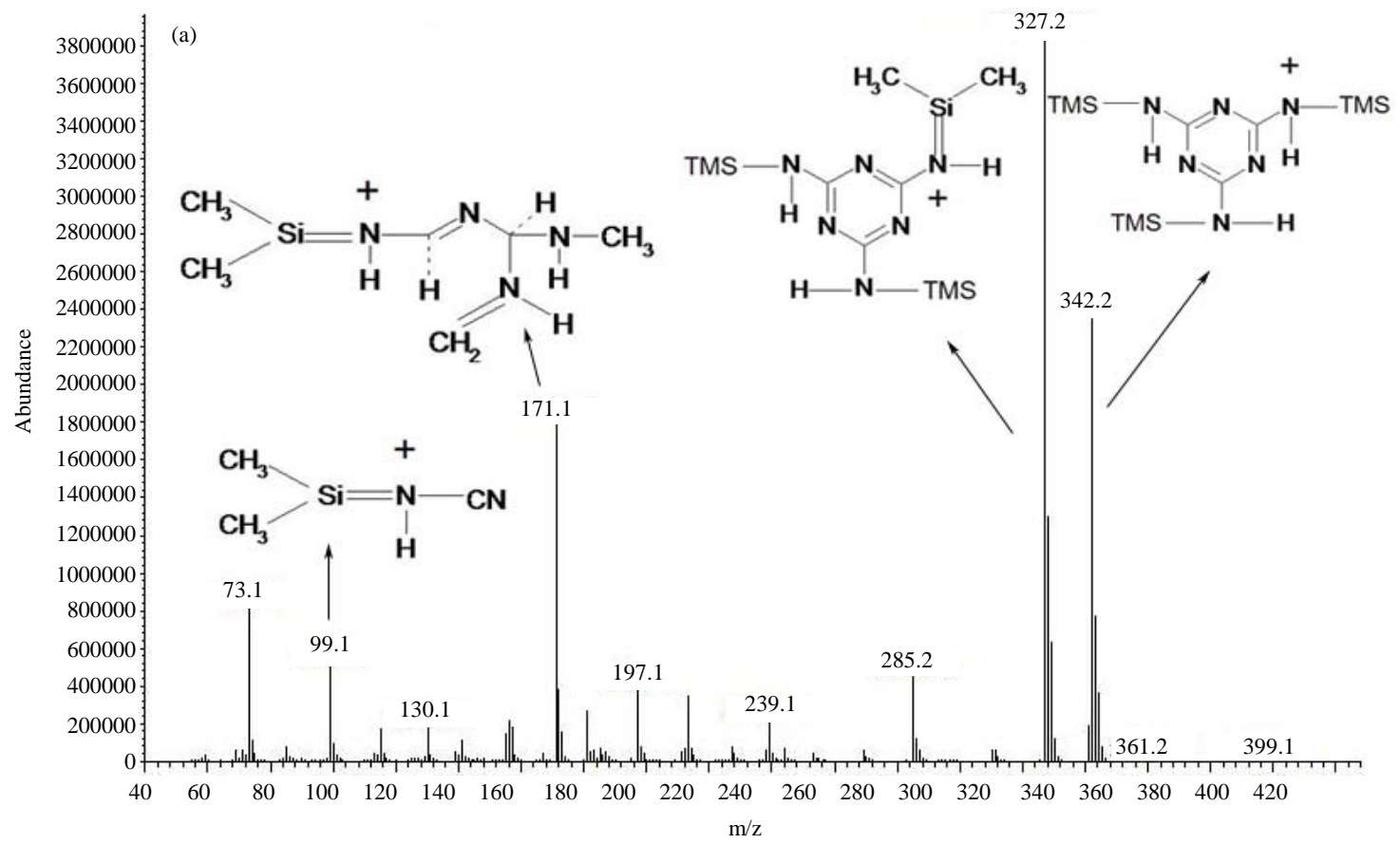

Fig. 1: Continued 

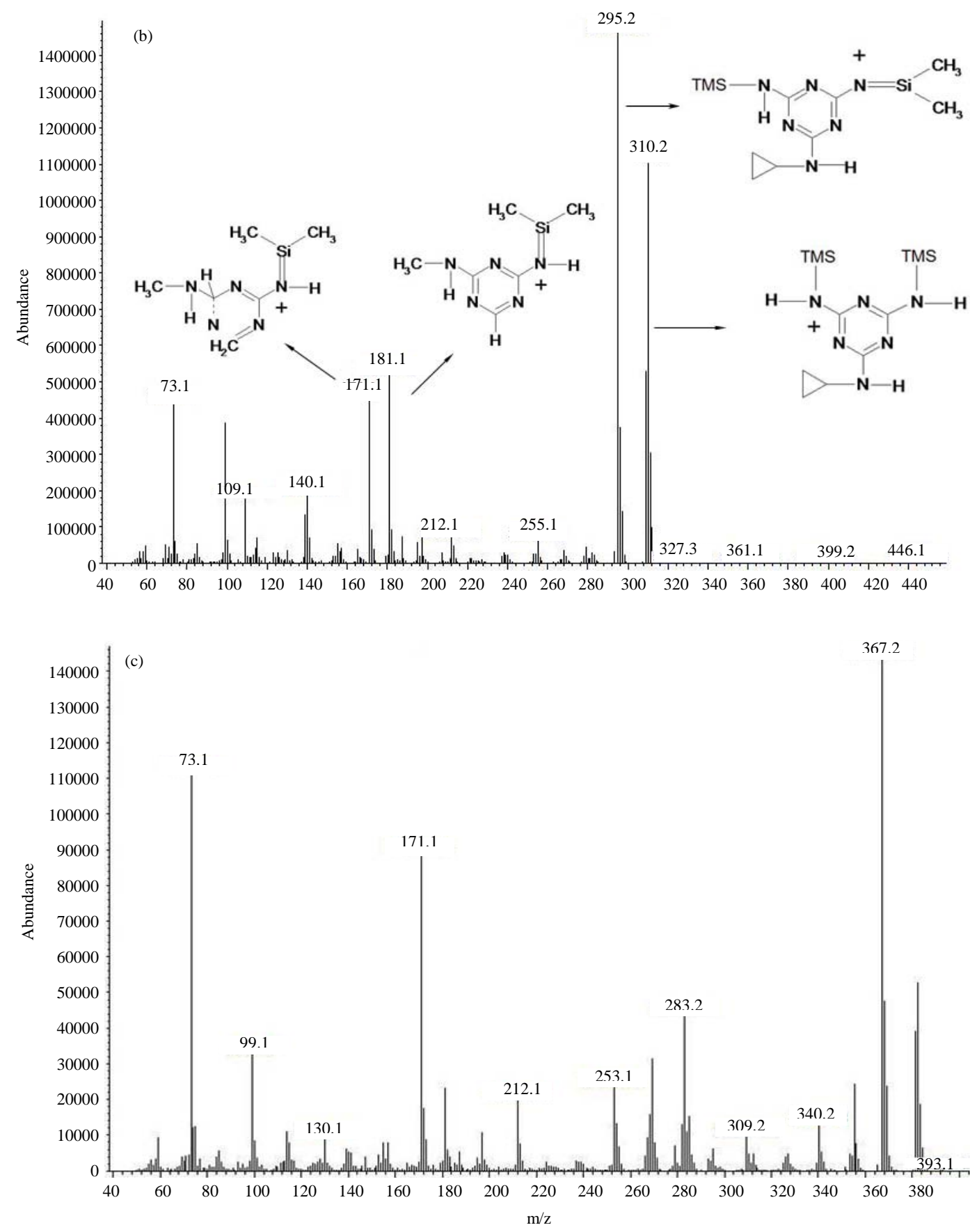

Fig. 1: (a) A full-scan spectrum and the postulated characteristic ion fragments of the trimethylsilyl derivative of melamine. The fragment structures were adapted from the Food Safety and Inspection Service except for $\mathrm{m} / \mathrm{z}$ 99; (b) A full-scan spectrum and the postulated characteristic ion fragments of the bi-substituted derivative of cyromazine. The fragment structures were adapted from the Food Safety and Inspection Service and (c) A full-scan spectrum of the tri-substituted derivative of cyromazine

through inspection of their full-scan mass spectra obtained via electron ionization at $70 \mathrm{eV}$. The $\mathrm{m} / \mathrm{z} 327$ and 295 were chosen as quantification ions for melamine and cyromazine, respectively.
Sample preparation: Commercial feed samples for poultry and swine were from the Ministry of Agriculture Feed Industry Centre (Beijing, China) which were submitted for melamine confirmation analysis in September 2008. Prior 
to analysis, the feeds were pulverized to pass through a $0.25 \mathrm{~mm}$ mesh screen. Fortified samples were prepared by adding appropriate amounts of the fortification solutions to the control feed samples and were allowed to stand at room temperature for at least $24 \mathrm{~h}$ before proceeding with extraction.

Extraction: A $5.0 \mathrm{~g}$ sample of feed was weighed into a $150 \mathrm{~mL}$ Erlenmeyer flask, $50.0 \mathrm{~mL}$ of $10 \mathrm{~g} \mathrm{~L}^{-1}$ trichloroacetic acid solution and $2.0 \mathrm{~mL}$ of $22 \mathrm{~g} \mathrm{~L}^{-1}$ lead acetate solution were added and sonicated for $20 \mathrm{~min}$. Then a portion of the mixture was transferred into a polypropylene centrifuge tube and centrifuged at $8000 \mathrm{rpm}$ for $10 \mathrm{~min}$ at $4^{\circ} \mathrm{C}$.

Cleanup with solid phase extraction: An Agilent SampliQ SCX Cartridge ( $60 \mathrm{mg}, 3 \mathrm{~mL}$, Newport, DE, USA) was used to cleanup the extracts. The cartridge was conditioned with $3 \mathrm{~mL}$ methanol followed by $3 \mathrm{~mL}$ water. A $3 \mathrm{~mL}$ aliquot of supernatant was applied to the conditioned cartridge and was allowed to flow at a rate of one drop per second. The column was then washed with $3 \mathrm{~mL}$ water and $3 \mathrm{~mL}$ methanol in succession and dried by applying a vacuum for $1 \mathrm{~min}$. The adsorbed target compounds on the column were eluted with $3 \mathrm{~mL}$ of $0.5 \%(\mathrm{v} / \mathrm{v})$ ammonium hydroxide/methanol into a glass derivatization vial by gravity. The eluate was evaporated to dryness under a gentle stream of nitrogen in a water bath at $50^{\circ} \mathrm{C}$. Calibration standards were prepared in the same time.

Derivatization: The derivatization vials were placed in an oven at $70^{\circ} \mathrm{C}$ for $10 \mathrm{~min}$ to remove any remaining moisture. After cooled to room temperature, $100 \mu \mathrm{L}$ of acetonitrile and $100 \mu \mathrm{L}$ of BSTFA with $1 \%$ TMCS were added and vortexed vigorously. The tightly capped vials were placed in an oven at $70^{\circ} \mathrm{C}$ for $30 \mathrm{~min}$ to complete the silylation reaction. Then $50 \mu \mathrm{L}$ acetone was added and vortexed. The final solution was used for GC-MS analysis.

\section{RESULTS AND DISCUSSION}

Selection of chromatograph columns: In previous reports, melamine and cyromazine can be separated using DB-17 (Toth and Bardalaye, 1987), DB-5MS (Ministry of Agriculture of P.R. China, 2007) or DB-Wax column (Yokley et al., 2000). In this study, three types of gas chromatograph columns including INNOWAX, DB-1701 and DB-5MS (Agilent J and W Scientific, Folsom, CA, USA) were compared with or without derivatizaiton. As a result, symmetrical and sharp peaks as well as high sensitivity were achieved on the DB-5MS column after derivatization.
Derivatization: It has previously been reported that melamine and cyromazine can be separated chromatographically without derivatization (Toth and Bardalaye, 1987; Yokley et al., 2000; Karras et al., 2007). However, in the present experiment when no derivatization was employed, peak tailing and inadequate sensitivity were observed and we subsequently employed a derivitization step in the protocol.

In previous studies, BSTFA with $1 \%$ TMCS has generally been chosen as derivatization reagent and the reaction conditions were 110 or $80^{\circ} \mathrm{C}$ for $1 \mathrm{~h}$ and $70^{\circ} \mathrm{C}$ for 30 or $45 \mathrm{~min}$ (FDA, 2007; Zhu et al., 2009). In this study, a reaction condition of $70^{\circ} \mathrm{C}$ for $30 \mathrm{~min}$ was employed, since higher temperatures would lead to considerable loss of solvents. The presence of water prevents formation of trimethylsilyl derivatives of the analytes (FDA, 2007), therefore, $10 \mathrm{~min}$ in an oven at $70^{\circ} \mathrm{C}$ after drying under nitrogen gas was a necessary measure to completely eliminate water vapor and avoid failure of derivatization, especially for cyromazine.

In contrast to previously developed methods (Zhu et al., 2009), acetonitrile instead of pyridine was used as the reaction medium to derivatize with melamine and cyromazine since pyridine is relatively toxic and has an unpleasant odor. The derivatization effect of the acetonitrile medium was generally comparable with that of pyrindine but the derivatization product would separate into two layers when the room temperature was below $20^{\circ} \mathrm{C}$ and the target derivatives did not equally distribute in the two layers. In addition, the distribution of the derivatives between the two layers would change with varying temperature. This created considerable variation in quantification. This phenomenon was particularly a problem in quantifying cyromazine. For cyromazine, two possible trimethylsilyl derivatives are generated (Fig. 1b and c); one is the bi-substituted derivative with characteristic ions at $\mathrm{m} / \mathrm{z}$ as $171,181,295$ and 310 and the other is the tri-substituted derivative which usually forms with prolonged heating or heating at higher temperatures with characteristic ions at $\mathrm{m} / \mathrm{z}$ as $171,253,269,283,367$ and 382 . It is found that the tri-substituted derivative mainly existed in the bottom layer of the mixture while the bi-substituted derivative mainly stayed in the upper layer after cooling. According to the research, neither the bi-substituted derivative nor the tri-substituted derivative in the upper or the bottom layer was appropriate for quantification of cyromazine due to considerable variation. In order to prevent stratification and develop an accurately quantitative method, $50 \mathrm{uL}$ acetone was added to the mixture. The bi-substituted derivative is used for quantification of cyromazine and reproducible results were subsequently obtained from multiple injections. As for the relative intensities of the characteristic ions of each target trimethylsilyl derivative (Table 1), the acceptable ranges of confirmation were established by 
calculating \pm 10 or $\pm 15 \%$ of the characteristic ion/base ion ratio determined with the $6 \mu \mathrm{g} \mathrm{mL} \mathrm{mL}^{-1}$ calibrating standard injected according to Commission Decision of the European Community (Commission Decision $2002 / 657 / \mathrm{EC}$ ). The relative intensities of characteristic ions for all standards and samples analyzed were within the appropriate ranges.

Optimization of sample extraction and cleanup: Melamine and cyromazine are usually extracted from a variety of matrices with organic solvents such as methanol and acetonitrile, often in combination with water, dichloromethane, diethylamine, ammonium carbonate or ammonium hydroxide (Yokley et al., 2000; Chou et al., 2003; FDA, 2007; Luan et al., 2007; Andersen et al., 2008; Filigenzi et al., 2008; Smoker and Krynitsky, 2008; Varelis and Jeskelis, 2008; Wei et al., 2009).

They can also be extracted with acidic aqueous solutions (Sancho et al., 2005; Heller and Nochetto, 2008; Zhu et al., 2009). Trichloroacetic acid solution was used for extraction in the current method, adapted from a previous study on the determination of melamine in feeds. The amidogens of melamine and cyromazine can be protonated in acidic solution and the protonated analytes are more easily retained on a cation exchange column without the need of acidifying the extracts as in the case with alkaline or neutral solvent extraction (Yokley et al., 2000; Smoker and Krynitsky, 2008; Varelis and Jeskelis, 2008). Furthermore, trichloroacetic acid in combination with lead acetate can precipitate proteins in the matrix to help further purify the extracts.
A $5 \%(\mathrm{v} / \mathrm{v})$ solution of ammonium hydroxide/ methanol has been commonly used as the elution solution applied on the cation exchange resin (Yokley et al., 2000; Andersen et al., 2008). As feed components are rather complex and variable, shoulder peaks interfered with the target peak when the $5 \%$ elution solution was used. Hence, 5, 2.5, 1, 0.5 and $0.25 \%(\mathrm{v} / \mathrm{v})$ ammonium hydroxide/methanol as elution solutions were tested for their effects in terms of recovery, precision and interference. As the ammonium hydroxide/methanol concentration declined, the interference around the target peak also decreased. However, when the concentration dropped to $0.25 \%$, recoveries were reduced for both of the analytes whereas the recoveries did not significantly differ when the ammonium hydroxide concentration ranged from $0.5-5 \%$ (Table 2). Thus, the optimal ammonium hydroxide/methanol concentration for elution was determined to be $0.5 \%(\mathrm{v} / \mathrm{v})$.

Method validation: The linear range of the calibration curve was $0.02-10.0 \mu \mathrm{g} \mathrm{mL}^{-1}$ with a correlation coefficient of 0.9999 for melamine and 0.9993 for cyromazine, respectively. The accuracy and precision of the method were evaluated according to recovery and Relative Standard Deviation (RSD), respectively. Three fortified samples at each spiked level were analyzed on three non-consecutive days. The results were shown in Table 3. For melamine, the average recoveries at levels between 0.1 and $50 \mathrm{mg} \mathrm{kg}^{-1}$ ranged from $84.2-99.5 \%$ with RSDs from $1.7-10.2 \%$. For cyromazine, the average recoveries at these spiked levels ranged from $84.5-96.8 \%$ with RSDs from $2.2-7.7 \%$.

Table 2: Comparison of recoveries and RSD among different concentrations of ammonium hydroxide/methanol elution solution ( $\mathrm{n}=6$ )

\begin{tabular}{lccc}
\hline & Melamine & & Cyromazine \\
Ammonium hydroxide/methanol (\%, v/v) & Recovery (\%) & RSD (\%) & Recovery (\%) \\
\hline 0.25 & 93.47 & 2.2 & 89.52 \\
0.5 & 110.15 & 1.3 & 107.79 \\
1 & 106.54 & 0.7 & 108.71 \\
2.5 & 106.90 & 2.9 & 105.31 \\
5 & 108.66 & 0.9 & 2.4 \\
\hline
\end{tabular}

Table 3: Recoveries of melamine and cyromazine from spiked feed samples $(n=9)$

\begin{tabular}{|c|c|c|c|c|c|}
\hline \multirow[b]{2}{*}{ Analyte } & \multirow[b]{2}{*}{ Spiked level (mg kg $\left.{ }^{-1}\right)$} & \multicolumn{3}{|c|}{ Recovery (\%) } & \multirow[b]{2}{*}{ RSD (\%) } \\
\hline & & Mean & Maximum & Minimum & \\
\hline \multirow[t]{5}{*}{ Melamine } & 0.1 & 99.5 & 110.3 & 83.2 & 10.2 \\
\hline & 0.5 & 90.8 & 96.8 & 84.2 & 5.4 \\
\hline & 5.0 & 84.2 & 89.3 & 79.5 & 4.5 \\
\hline & 10.0 & 94.0 & 100.8 & 86.5 & 3.9 \\
\hline & 50.0 & 90.4 & 91.8 & 88.8 & 1.7 \\
\hline \multirow[t]{5}{*}{ Cyromazine } & 0.1 & 89.7 & 101.6 & 82.1 & 7.6 \\
\hline & 0.5 & 88.8 & 95.1 & 83.6 & 5.5 \\
\hline & 5.0 & 84.5 & 87.9 & 79.4 & 3.7 \\
\hline & 10.0 & 96.8 & 107.4 & 86.8 & 7.7 \\
\hline & 50.0 & 91.3 & 92.9 & 89.0 & 2.2 \\
\hline
\end{tabular}




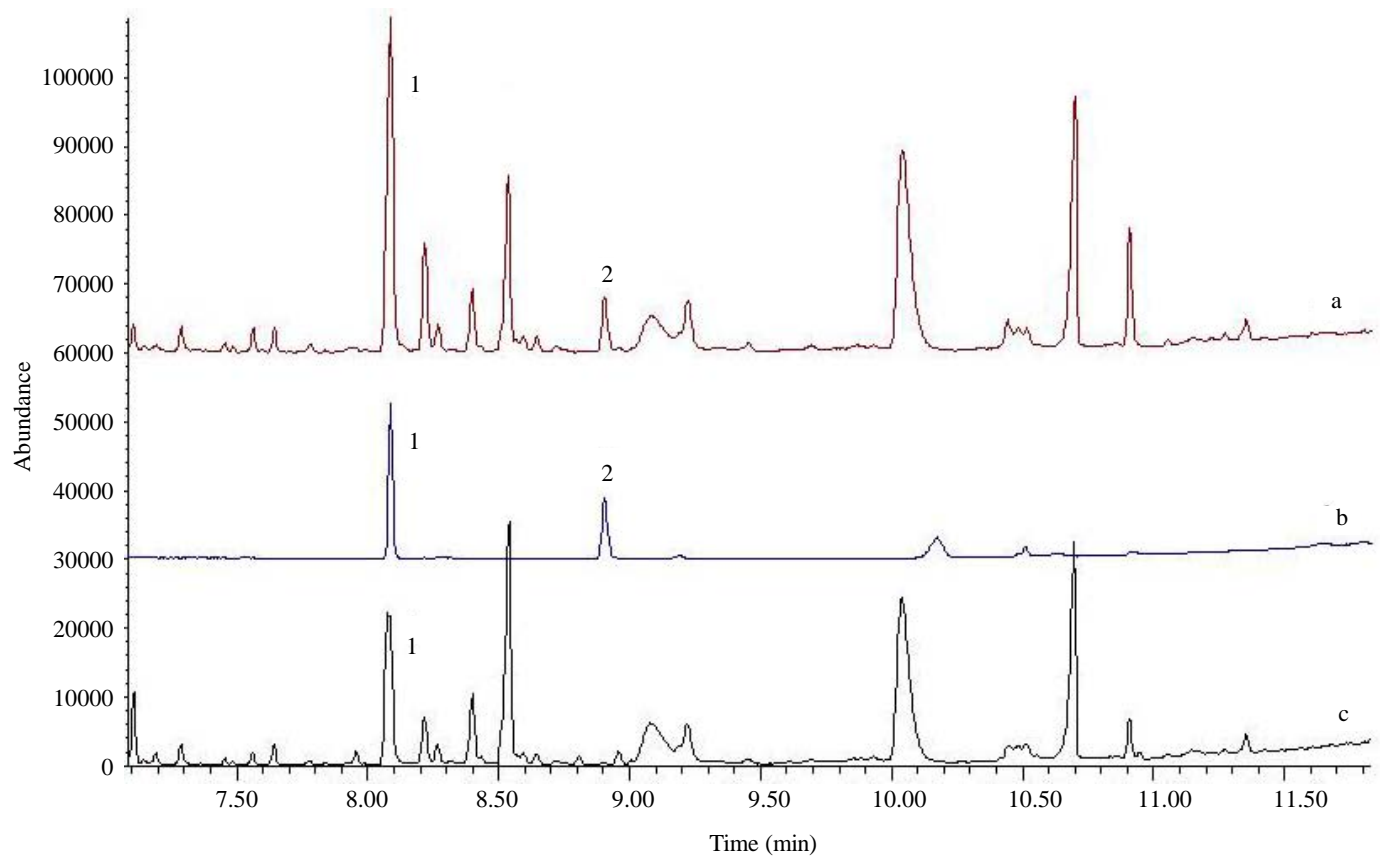

Fig. 2: The total ion chromatograms of the spiked sample (a), standard (b) and control sample (c) at $0.1 \mathrm{mg} \mathrm{kg}^{-1}$. Peaks 1 and 2 are melamine and cyromazine, respectively

The limits of detection and quantification (LOD and LOQ) for cyromazine were 0.03 and $0.10 \mathrm{mg} \mathrm{kg}$, respectively calculated from 3 and 10 times the background noise of blank sample at the retention time of the compound. As the control sample contained $0.09 \mathrm{mg} \mathrm{kg}^{-1}$ melamine, the LOQ of melamine in feed was estimated to be $0.10 \mathrm{mg} \mathrm{kg}^{-1}$ (as the lowest spiked level in control feed) while the LOD for melamine can not be ascertained.

The recoveries and RSDs of melamine and cyromazine at the concentration level of the LOQ are shown in Table 3. The average recoveries of melamine and cyromazine at the LOQ level were both above $89 \%$ with RSD $<11 \%$. Typical total ion chromatograms of the standard, control and spiked sample at $0.1 \mathrm{mg} \mathrm{kg}^{-1}$ are shown in Fig. 2.

Application: The method was applied to 20 commercial feed samples (including swine, broiler and layer feeds). Of interest was the finding that approximately $30 \%$ of the samples $(6 / 20)$ slightly exceeded the maximum permitted melamine residue level $\left(2.5 \mathrm{mg} \mathrm{kg}^{-1}\right.$ in feed) set by the Chinese Ministry of Agriculture and CAC new rules (FAO, 2010).

There are many sources (such as soil, pesticide, plastic wares, laboratory materials, etc.) which might contaminate feeds and contribute to the baseline of melamine in feeds. About $30 \%$ of the analyzed feed samples contained cyromazine that were within the acceptable tolerance level (5 mg kg-1) while no cyromazine was detected in the remained samples.

\section{CONCLUSION}

In this study we present a new method for the simultaneous determination of melamine and cyromazine in animal feeds. The method differs from previous methods mainly in the sample cleanup and derivatization steps. The optimal ammonium hydroxide/methanol concentration for elution was determined to be $0.5 \%(\mathrm{v} / \mathrm{v})$ instead of $5 \%(\mathrm{v} / \mathrm{v})$ which not only reduced impurity peaks and increased accuracy of quantification but also improved the general performance of the evaporation and derivatization steps and saved wear and tear on the instrument.

When acetonitrile was used as the derivatization reaction medium instead of pyridine, stratification of the derivatization product occurred and the bi and trisubstituted derivatives of cyromazine were found unequally distributed in the two layers. In order to prevent stratification and develop an accurately quantitative method, acetone was added to the mixture and reproducible results were subsequently obtained from multiple injections. The method has been successfully 
validated and used on analysis of commercial feed samples showing that it can be a routine tool for surveillance and evaluation of melamine and cyromazine in animal feeds.

\section{ACKNOWLEDGEMENT}

The researchers are grateful to Ministry of Agriculture of the People's Republic of China for financial support and also wish to acknowledge Prof. Philip Thacker for his suggestions and English editing.

\section{REFERENCES}

Andersen, W.C., S.B. Turnipseed, C.M. Karbiwnyk, S.B. Clark and M.R. Madson et al., 2008. Determination and confirmation of melamine residues in catfish, trout, tilapia, salmon and shrimp by liquid chromatography with tandem mass spectrometry. J. Agric. Food Chem., 56: 4340-4347.

Arnold, E., 1990. Cyromazine. Chemical Safety Information from Intergovernment Organizations. http://www. inchem.org/documents/jmpr/jmpmono/ v90pr06.htm.

Brown, C.A., K.S. Jeong, R.H. Poppenga, B. Puschner and D.M. Miller et al., 2007. Outbreaks of renal failure associated with melamine and cyanuric acid in dogs and cats in 2004 and 2007. J. Vet. Diagn. Invest., 19: $525-531$

Cabras, P., M. Melon and L. Spanedda, 1990. Highperformance liquid chromatographic separation of cyromazine and its metabolite melamine. J. Chromatogr., 505: 413-416.

Chou, S.S., D.F. Hwang and H.F. Lee, 2003. High performance liquid chromatographic determination of cyromazine and its derivative melamine in poultry meats and eggs. J. Food Drug Anal., 11: 290-295.

Cook, A.M., H. Grossenbacher and R. Hutter, 1984. Bacterial degradation of $\mathrm{N}$-cyclopropylmelamine. The steps to ring cleavage. Biochem. J., 222: 315-320.

$\mathrm{FAO}, 2010$. Codex alimentarius commission meeting in Geneva. July 6, 2010 Geneva/Rome. http://www.fao. org/news/story/en/item/43719/icode/.

FDA (Food and Drug Administration), 2007. GC-MS screen for the presence of melamine, ammeline, ammelide and cyanuric acid. Version 2.1 . http:/www.fda.gov/cvm/gcmsmelamine.htm.

Filigenzi, M.S., B. Puschner, L.S. Aston and R.H. Poppenga, 2008. Diagnostic determination of melamine and related compounds in kidney tissue by liquid chromatography/tandem mass spectrometry. J. Agric. Food Chem., 56: 7593-7599.
Heller, D.N. and C.B. Nochetto, 2008. Simultaneous determination and confirmation of melamine and cyanuric acid in animal feed by zwitterionic hydrophilic interaction chromatography and tandem mass spectrometry. Rapid Commun. Mass Spectrometry, 22: 3624-3632.

Karras, G., D. Savvas, G. Patakioutas, P. Pomonis and T. Albanis, 2007. Fate of cyromazine applied in nutrient solution to a gerbera (Gerbera jamesonii) crop grown in a closed hydroponic system. Crop Prot., 26: 721-728.

Lim, L.O., S.J. Scherer, K.D. Shuler and J.P. Toth, 1990. Disposition of cyromazine in plants under environmental conditions. J. Agric. Food Chem., 38: 860-864.

Luan, W., Y. Fang and J. Zweigenbaum, 2007. A total solution for analysis of melamine and cyanuric acid in pet food by GC/MS and LC/MS/MS. Agilent Application Note: 5989-7546EN, Agilent Technologies: United States, pp 1-8.

Puschner, B., R.H. Poppenga, L.J. Lowenstine, M.S. Filigenzi and P.A. Pesavento, 2007. Assessment of melamine and cyanuric acid toxicity in cats. J. Vet. Diagn. Invest., 19: 616-624.

Sakuma, T. and A. Schreiber, 2008. A new, fast and sensitive LC/MS/MS method for the accurate quantitation and confirmation of melamine and cyanuric acid in pet food samples. Application Note: Melamine and cyanuric Acid. Applied Biosystems/ MDS Sciex: Foster City, CA, pp: 1-4, Publication 114AP62-02.

Sancho, J.V., M. Tbanez, S. Grimalt, O.J. Pozo and F. Hernandez, 2005. Residue determination of cyromazine and its metabolite melamine in chard samples by ion-pair liquid chromatography coupled to electrospray tandem mass spectrometry. Anal. Chimica Acta, 530: 237-243.

Smoker, M. and A.J. Krynitsky, 2008. Interim method for determination of melamine and cyanuric acid residues in foods using LC-MS/MS: Version 1.0. http://fooddrugcompliance.com/blog/283/interimmethod-for-determination-of-melamine-and-cyanuricacid-residues-in-foodsusing-lc-msms-version-10/.

Toth, J.P. and P.C. Bardalaye, 1987. Capillary gas chromatographic separation and mass spectrometric detection of cyromazine and its metabolite metamine. J. Chromatogr., 408: 335-340.

Vail, T., P.R. Jones and O.D. Sparkman, 2007. Rapid and unambiguous identification of melamine in contaminated pet food based on mass spectrometry with four degrees of confirmation. J. Anal. Toxicol., 31: 304-312. 
Varelis, P. and R. Jeskelis, 2008. Preparation of [13C3]melamine and [13C3]-cyanuric acid and their application to the analysis of melamine and cyanuric acid in meat and pet food using liquid chromatography-tandem mass spectrometry. Food Additives Contam. Part A, 25: 1208-1215.

Wang, J.R. and L.Y. Zhang, 2006. Simultaneous determination and identification of furazolidone, furaltadone, nitrofurazone and nitrovin in feeds by high performance liquid chromatography and liquid chromatography-mass spectrometry. J. Liq. Chromatogr. Related Technol., 29: 377-390.

Wei, R., R. Wang, Q. Zeng, M. Chen and T. Liu, 2009. High-performance liquid chromatographic method for the determination of cyromazine and melamine residues in milk and pork. J. Chromatogr. Sci., 47: 581-584.
Xia, K., J. Atkins, C. Foster and K. Armbrust, 2010. Analysis of cyromazine in poultry feed using the QuEChERS method coupled with LC-MS/MS. J. Agric. Food Chem., 58: 5945-5949.

Yokley, R.A., L.C. Mayer, R. Rezaaiyan, M.E. Manuli and M.W. Cheung, 2000. Analytical method for the determination of cyromazine and melamine residues in soil using LC-UV and GC-MSD. J. Agric. Food Chem., 48: 3352-3358.

Zhu, X.Z., S.H. Wang, Q. Liu, Q. Xu, S. Xu and H. Chen, 2009. Determination of residues of cyromazine and its metabolite, melamine, in animal-derived food by gas chromatography-mass spectrometry with derivatization. J. Agric. Food Chem., 57: 11075-11080. 